\title{
Some Aspects of Functional Results of Treatment in Traumatic Cervical Spinal Cord Injured Patients *
}

\section{J. Kiwerski, MD}

Rehabilitation Clinic of Warsaw Medical Academy, Konstancin, Poland.

Key words: Spinal cord injury; Conservative treatment; Surgical treatment; Functional results.

In the period 1965-1984, 1241 patients with cervical cord injuries were treated in the Rehabilitation Clinic at Konstancin. This communication analyses some aspects of the functional results in the series. The degree of the injuries and the method of treatment are recorded. It has been found that the degree of the spinal cord injury on admission is a decisive factor in the prognosis but even in the tetraplegic this does not preclude improvement, provided expert treatment is commenced at an early stage. For example, $17^{\circ}$ o were eventually able to walk. The age of the patient is also important-after 40 years of age the chances of a good functional result becomes less and the mortality greater. The method of treatment is also important as the results of surgery appear better than those after conservative methods.

Table I Functional results of treatment of tetraplegic patient

\begin{tabular}{lcccccccc}
\hline & $\begin{array}{c}\text { Without } \\
\text { orthopaedic } \\
\text { devices }\end{array}$ & $\begin{array}{c}\text { With } \\
\text { a cane }\end{array}$ & $\begin{array}{c}\text { With } \\
\text { crutches }\end{array}$ & $\begin{array}{c}\text { With } \\
\text { walking } \\
\text { aids }\end{array}$ & Independent & Dependent & Mortality & Total \\
Age & 6 & 8 & 7 & 3 & 37 & 46 & 13 & 120 \\
Up to 20 & 13 & 15 & 18 & 5 & 68 & 96 & 45 & 260 \\
$21-40$ & 12 & 7 & 11 & 7 & 28 & 65 & 73 & 203 \\
$41-60$ & 4 & 3 & 2 & 2 & 9 & 28 & 80 & 128 \\
Over 60 & 35 & 33 & 38 & 17 & 142 & 235 & 211 & 711 \\
Total & & & & &
\end{tabular}

\section{Conclusions}

1. The degree of spinal cord injury on admission is decisive for the functional results of treatment. Four-limb paralysis on admission, however, does not

$\star$ (Summary of paper). 
Table II Functional results of treatment of tetraparetic patients

\begin{tabular}{lcccccrrr}
\hline & $\begin{array}{c}\text { Without } \\
\text { orthopaedic } \\
\text { devices }\end{array}$ & $\begin{array}{c}\text { With } \\
\text { a cane }\end{array}$ & $\begin{array}{c}\text { With } \\
\text { crutches }\end{array}$ & $\begin{array}{c}\text { With } \\
\text { walking } \\
\text { aids }\end{array}$ & Independent & Dependent & Mortality & Total \\
Age & 64 & 3 & 3 & 1 & 1 & 1 & - & 73 \\
Up to 20 & 125 & 7 & 6 & 4 & 2 & 1 & 1 & 146 \\
$21-40$ & 118 & 12 & 10 & 9 & 3 & 5 & 8 & 165 \\
$41-60$ & 94 & 12 & 6 & 4 & -6 & 9 & 21 & 146 \\
Over 60 & 401 & 34 & 25 & 18 & 6 & 16 & 30 & 530 \\
Total & & & & & & & &
\end{tabular}

preclude the chances for functional improvement, provided proper treatment is started early.

2. Functional results of treatment are to a certain extent dependent on the age of the patient. While age is not a very significant factor up to 40 years, it becomes crucial in those who are older.

3. The results of surgical treatment are better than with conservative measures. Thus it is advisable to make a wider use of surgical procedures in the treatment of spinal cord injuries. 